\title{
Discussion on Capital Plan of Small and Micro Enterprises
}

\author{
Rong Wu \\ Kunming University of science and technology Oxbridge College, Kunming Yunnan, China, 650093
}

Keywords: small and micro enterprises; capital plan; risk prevention

\begin{abstract}
In recent years, small and micro enterprises in China have developed vigorously, which play an important and fundamental roles in attracting employment and boosting economic development. Apart from the gradual improvement of external developments and the further reduction of development barriers, the key factors for the healthy growth of small and micro enterprises also come from improving the internal management level and operating ability. Starting from the actual operation, this paper suggests that small and micro enterprises should pay attention to and use the financial management thinking, plans the utilization of enterprise funds scientifically, improves the ability and efficiency of fund usage and enhances the ability to prevent and control the enterprise financing risks.
\end{abstract}

\section{Introduction}

At present, small and micro enterprises in China are playing an increasingly important role in alleviating employment pressure, promoting scientific and technological innovation, and promoting steady economic growth (Dexian, 2012). However, small and micro enterprises have always been vulnerable groups in the market competition, so that the development of small and micro enterprises has become an important field of business, academia and related management departments. In 2011, "The notice about the issue of standard of small and medium enterprises by the Ministry of industry and information technology, the National Bureau of statistics, the national development and Reform Commission, the Ministry of Finance" was issued, in which the small and micro enterprises were clearly defined (2014). The domestic researches on small and micro enterprises is short and limited. Most of the researches focus on the external factors that hinder the development of small and micro enterprises, such as financing difficulties, high labor costs, high land costs, high logistics costs, high taxes and fees, high transaction costs, imperfect policies and etc.. As a result, the external development conditions of China's small and micro enterprises have been significantly improved after the continuous efforts in the "12th Five-Year" period. However, the actual situation is that the absolute increment of small and micro enterprises showed an upward trend for several years, but the the annual number of cancellation accounts for more than $70 \%$, forming a quick replacement situation (Jinwen, 2012).

\section{Overview of Small and Micro Enterprises}

Small and micro enterprises are collectively known as small enterprises, micro enterprises, family workshops and individual businesses. The scale and output value of these enterprises are small, the property rights and management rights are highly unified, and the types of products (services) are simple and its employees are less. In March 2014, the State Administration of Industry and Commerce issued "The report on the development of small and micro enterprises in China", by which the latest development of small and micro enterprises in China is presented. Data show that the main characteristics of China's small and micro enterprises are as below ((Qun, 2012)).

(1) The rapid growth of the number has significantly boosted economic growth. In 2013, the number of small and micro enterprises reached 56.06 million, and then increased to 65.30 million in 2014, accounting for more than $90 \%$ of the total number of enterprises. Therefore, the small and micro enterprises have become the basic force of social economy. According to the third national 
economic census in 2013, second and third industrial enterprises realized operating income of 228.1 trillion yuan in China, much more than 123.9 trillion year compared with 2008, and the growth rate was 118.9\%. From 2008 to 2013, the new small and micro business achieved operating income 26.9 trillion, accounting for $21.7 \%$ of the second and third industry and pulling the second and third industry income by $25.8 \%$. The small and micro enterprises stimulate the vitality of markets and constantly release potential into all possible fields. There is no doubt that small and micro enterprises are becoming an innovative impetus to promote China's economic development at present and in future (Xiaosong, 2014).

(2) Absorption of employment solving the problem of people's livelihood. In 2013, China's employment population is about 767 million, and small and micro enterprises absorb about 150 million, more than $70 \%$ of which are new employment and reemployment. According to statistics in 2014, the absorption of employment by small and micro enterprises reached 250 million, and the absolute ratio of the number of small and micro enterprises involved in the total number of employment is $19.56 \%$ in 2013 and $32.38 \%$ in 2014 . The statistics also show that the absorption of employment by small and micro enterprises is larger that that by large and medium enterprises, which solve $70 \% \sim 80 \%$ urban employment and rural surplus labor force. At the same time, it becomes the main carrier of primary employment and reemployment.

(3) Lack of core competitiveness and short operating life. Most of the small and micro enterprises in China are at the bottom of the industrial chain, providing low levels of products and services, and do not have the core competitiveness. Therefore, it is at a distinct disadvantage in the competition with large scale enterprises. According to statistics in 2014 , only $12 \%$ of small and micro enterprises maintained more than $30 \%$ growth, and others were faced with the situation that insufficient market demand and difficult product sales. Among the small and micro enterprises with difficulties, $58.08 \%$ of them was hindered by the pressure of market competition, and $23.74 \%$ of them reflected the shortage of products. In addition, the survey also found that more that $30 \%$ of small and micro enterprises founders have had many entrepreneurial experience, and then the average life of small and micro enterprises in China is about 3.7 years, compared with 6.7 years in the United States and 12 years in Japan.

(4) High concentrated labor and low profit. The small and micro enterprises involved in extensive industries, covering most of the low sectors of industrial chains, such as product processing, resource development and low level service. The labor intensity and threshold of these industries are relatively low, leading to the rapid growth of small and micro enterprises, saturated markets and low profit margins.

(5) Uneven development, industrial and regional divisions. Data show that the development level and industrial characteristics of small and micro enterprises show a large contrast, due to the level of economic development in various regions, industrial policy guidance, differences in industrial layout. At the same time, the attitude of local governments towards small and micro enterprises is different, resulting in the policy environment of small and micro enterprises is not the same. In the industry distribution, China's small and micro enterprises are mainly concentrated in the industry, wholesale and retail, leasing and business services, the number of which accounts for more than $60 \%$ of the total number of small and micro enterprises. In the geographical distribution, $60 \%$ of small and micro enterprises located in coastal areas (about 11 provinces) in China. At present, the number of small and micro enterprises in the coastal areas has dropped slightly, the number of small and micro enterprises in the less developed western regions has increased rapidly, and the small and micro enterprises accounted for about $70 \%$ of the total increase of the national enterprises, eventually the characteristics of industrial clusters in some central areas have begun to highlight.

(6) Unscientific management, leading to low risk management. Most of the small and micro enterprises generally lack standardized managements, such as the simple financial management, unreasonable organization and human resources disposition, weak learning capacity and low innovation and enthusiasm. In addition, changing external environments, such as economic crisis, changing national policies, also lead to capital chain rupture and withdrawals from markets. 


\section{The Cost of Small and Micro Enterprises}

The small and micro enterprises have four main aspects when considering its operating costs due to its small and simple business, respectively are the cost of means of production, management cost, human resources cost and financing cost. In general, there is a big difference in the specific content of the cost due to different industries of the small and micro enterprises. According to the statistical data, this paper analyzed the cost of three representative small and micro enterprises in accordance with the industry concentration degree.

(1) High-tech small and micro enterprises. The cost of means of production involves instruments and equipment, leasing or construction of working sites and the research and development of techniques. The cost of each procurement activity continues to rise. Among them, the cost of research and development accounted for the highest. In general, there are two stages of researches in small and micro enterprises, respectively are research stage and development stage. The human resource cost includes salaries and benefits. Most of the enterprises utilize share method to attract core talents, so that the elasticity of this cost is great. At the same time, the recruitment cost of general technical personnel is greatly influence by the development of industries. The management cost is the conventional administrative expenses, involving various technical patent managements, travels and negotiations. The financing cost would be higher because of the large investment in the earlier stage and the uncertain effect of the later result transformation. Therefore, the financing cost of the high-tech small and micro enterprises is higher.

(2) Industrial small and micro enterprises. The cost of means of production involves the purchasing cost, management cost, human resource cost. If the purchase channel is simple, leading to the shortage of raw material, the cost of means of production would be increased gradually. Industrial small and micro enterprises are mostly in the low end of the industrial chain, so that the quality of business owners and practitioners is low as well, leading to relaxed management and more hidden costs. At the same time, the cost consciousness of small and micro enterprises are indifferent, which also increases the management cost. Due to low profit of industrial small and micro enterprises, the investment of staff training is less, which often leads to the rise of non systematic costs. In addition, enterprises have to comply with the policy of more than $7 \%$ increment of salaries, as well as inflation, so that its human resource cost increases rapidly. Because of small scales, the traditional financing channels are unwilling to lend.

(3) Retail small and micro enterprises. With the rise of e-commerce, the "online" and "offline" differentiation of large-scale retail industry has been triggered. Online retail is online shop, offline retail is entity store. The development of the real retail industry is mainly affected by the geographical location and the size of the individuals' flow, and then its cost includes operation cost, rent, water and electricity prices and the growth of wage for employees. To online retail, the cost is mainly the annual average growth of $20 \%$ of the logistics cost. Mixed retail combines online and offline retail at the same time, so that it could face the pressure from offline stores and online stores.

\section{The Capital Plan of Small and Micro Enterprises}

Capital plan is an important part of financial management, which helps enterprises maintain financial liquidity and appropriate capital structure, and seeks maximum benefits with limited funds. It involves the raising and using of capitals. The survival and development of small and micro enterprises is the prerequisite, and the guarantee of survival is capital. The current small and micro enterprises generally lack awareness of financial management, the use of funds is unscientific and unreasonable, greatly affecting the level of business management. Therefore, small and micro enterprises need to improve the ability of financial management, so as to survive and seek development for a long time. Small and micro enterprises should consider their own operating conditions and development stages when making capital plans. According to the industry life cycle, the initial stage of the enterprise is immature so that the enterprise generally lacks competitive advantage at this time, and the goal of the capital plan is to obtain sufficient funds to ensure the normal operation of the enterprises. When the operation of small and micro enterprises has been 
more than 3 years, small and micro enterprises should consider increasing the accumulation of competitiveness in addition to ensuring normal operation.

According to the general principles of financial management, small and micro enterprises should first consider the positioning of enterprises when making capital plans, estimate the production, sales, development, investment and other financing activities in the future period, and formulate the corresponding comprehensive balance plan of funds to form the prior control of funds. Thus, they can guarantee the liquidity and security of funds, improve the efficiency of the use of funds, reduce the cost of capital and achieve the effect of reasonable control of operational risk. the preparation of capital plan in small and micro enterprises is relatively simple due to its small size and simple business. However, four important financial management projects: operating activities, capital activities and assets, investment income and profit distribution and financing should be carefully considered.

(1) Funds for operating activities

1) Capital inflow

Sales inflow. Enterprises need to develop capital plan in accordance with its sales conditions, which could be divided into pre-sale, cash sale and credit sale. Here, pre-sale and credit sale should give clear indication of precollection and settlement according to the period of payment or historical collection in the sales contract.

Other inflow. Other capital plan according to the labor contract, lease contract and other contracts.

2) Capital outflow

Procurement of raw materials and acceptance of labor services. Small and micro enterprises should make capital plan according to production plan, pay attention to give clear indication of precollection and settlement. In addition, they should also notice the procurement expenditure according to agreement of payment terms, account periods and payment methods.

Salary and compensation expenditure. Small and micro enterprises should make capital plan according to salary systems, business plans and incentive policies.

Other outflow. Small and micro enterprises should first identify what types of businesses are classified into cost items, and then make the capital according to the expense budget, related agreements and contracts and experiences of counterparts. It is essential that there is no amortization of intangible assets, amortization of long-term deferred expenses and depreciation expense. According to the estimation of operation and the proportion of monthly tax expenditure to sales in previous years, small and micro enterprises could estimate tax amount. If there is a tax refund plan, small and micro enterprises should write down current capital plan.

3) Other income and expense

The enterprises should compile the capital plan according to the historical data or related agreements/contracts. The capital plan includes nonoperating income and expense, temporary receipts and suspense payments.

(2) Capital activities and asset projects

Capital activities. small and micro enterprises that have been operating for more than 3 years need to consider the scale expansion. Enterprises should add the investment spending and investment outlays into capital plan according to their development orientation, business plan and decisions of investment projects. If the enterprise have been operating for more than 3 years and there is no scale expansion needs, they could also compile their investment spending and investment outlays into capital plan according to their financing methods and products.

Asset projects. Small and micro enterprises could estimate payments and compile capital plan according to the investment plan and schedule during business activities. In addition, the procurement plan could be completed based on the investment plan and schedule during business activities as well. If the pre-payment has not been completed, small and micro enterprises should improve the capital plan based on the completion of contracts and their payment period. If enterprises need to tackle with intangible assets, fixed assets and other long-term assets, they should 
compile the capital plan in accordance with the asset depreciation period, storage situation and the market of scrap materials.

(3) Profit distribution and investment income

Profit distribution. Small and micro enterprises compile the payment plan according to their profit distribution plan.

Investment income. If the enterprises are investors, small and micro enterprises should compile the capital plan based on their revenue-sharing proposal and investment disposals.

(4) Fund-raising projects

Investment absorption. Small and micro enterprises compile the capital plan according to their growth need, operation plan and investment decision.

Stock financing. Small and micro enterprises compile the plan of capital inflow and outflow plan according to the maturity of the financing contract, renew period, contract lending rate.

After the completion of the above four items, it is necessary to check the capital plan. First of all, it is essential to check whether the compilation procedures of capital plan and capital budget are correct and whether the goals are consistent. Furthermore, enterprises should study whether the capital plan has improper accounts, such as getting rid of short-term loan using long-term loan. To sum up, excellent capital plan could ensure the liquidity and safety of small and micro enterprises' funds, so as to improve the efficiency of capital use, reduce the capital use cost and achieve the effect of reasonable control of operational risk.

\section{Conclusion}

To sum up, financial management thinking and capital plan can directly improve the level of enterprise management, enhance the competitiveness and promote stable development of small and micro enterprises in the markets. The establishment of financial management philosophy is to ensure the accuracy of the investment and financing of small and micro enterprises, and the guarantee of the good financial functioning of enterprises, which is beneficial for small and micro enterprises to promote their own quality in the fierce market competition.

\section{References}

[1] Dexian, Huang, 2012. Discussion on the problems of financial management in small and micro enterprises, Guide to Business. 11, pp.56-57.

[2] Jinwen, Liu, 2012. Research on loan problems of small and medium enterprises based on the dynamic game among small and medium enterprises, banks and governments, Financial Regulation. 9, pp.69-84.

[3] National small and micro enterprises development report group of Administration of industry and commerce, 2014. Report on the development of small and micro enterprises in China (Abstract), China Industry \& Commence News.

[4] Qun, Yin, 2012. Research on Financial Support to Small and Micro Enterprises of Policy Banks During Market, Hubei University of Technology. Wuhan.

[5] Xiaosong, Zhang, 2014. First Pubilishment of "Family Asset” of Small and Micro Enterprises, China Quality Daily. 